
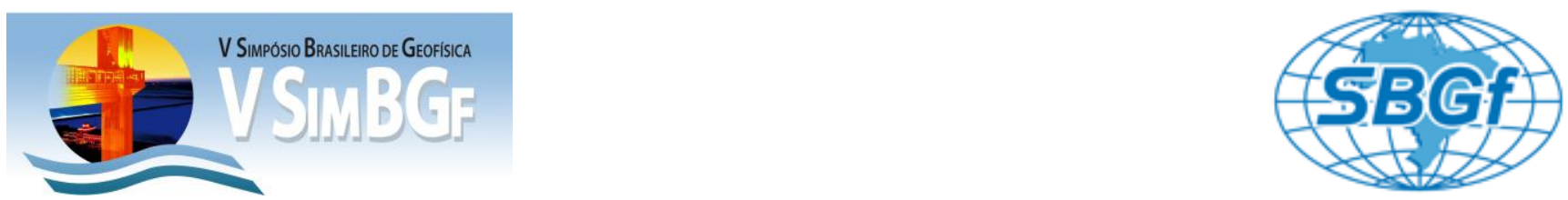

\title{
Estudo do manto superior no Brasil Central utilizando Tomografia Sísmica de tempo de percurso
}

Paulo Araújo de Azevedo* (Instituto de Geociências - Universidade de Brasília/UnB)

Marcelo Peres Rocha (Instituto de Geociências - Universidade de Brasília/UnB)

José Eduardo Pereira Soares (Instituto de Geociências - Universidade de Brasília/UnB)

Reinhardt Fuck (Instituto de Geociências - Universidade de Brasília/UnB)

Copyright 2012, SBGf - Sociedade Brasileira de Geofísica

Este texto foi preparado para a apresentação no V Simpósio Brasileiro de Geofísica, Salvador, 27 a 29 de novembro de 2012. Seu conteúdo foi revisado pelo Comitê Técnico do V SimBGf, mas não necessariamente representa a opinião da SBGf ou de seus associados. É proibida a reprodução total ou parcial deste material para propósitos comerciais sem prévia autorização da SBGf.

\section{Resumo}

Apresentamos resultados da aplicação do método geofísico de Tomografia Sísmica de tempo de percurso com ondas $\mathrm{P}$ em uma área localizada no Brasil Central. O objetivo do trabalho foi estudar o manto superior, buscando verificar a possível influência do Lineamento Transbrasiliano em profundidades litosféricas, bem como estudar os efeitos na litosfera relacionados à colisão entre os crátons Amazônico e do São Francisco durante o Neoproterozóico. Foram obtidas imagens de anomalias de velocidade sob a área de estudo, tendo sido observadas tendências de baixas velocidades na direção NE-SW, que concordam com o trend principal do Lineamento Transbrasiliano. Altas velocidades foram observadas nos crátons Amazônico e do São Francisco.

\section{Introdução}

Várias informações a respeito das propriedades físicas de um meio podem ser obtidas utilizando-se métodos tomográficos. Neste método, utiliza-se arranjo de receptores que registram as chegadas das ondas sísmicas geradas a partir de uma fonte qualquer, e que percorrem o meio subjacente a este arranjo. Devido à variação nas propriedades físicas do meio, a velocidade das ondas varia, fazendo com que estas cheguem antes, ou depois, do tempo esperado caso o meio fosse homogêneo. Nos resultados de Tomografia Sísmica são geradas imagens em duas (2D) ou três (3D) dimensões da distribuição das propriedades físicas do meio, geralmente em termos de variações da sua velocidade. Estas imagens podem ser interpretadas como variações de temperatura e/ou composição, sendo relacionadas às estruturas geológicas. A área de estudo (Figura 1) está localizada em sua maior parte na Província Tocantins, cobrindo também a parte sudeste do Cráton Amazônico e a parte sul da Bacia do Parnaíba. A área é atravessada pelo Lineamento Transbrasiliano, uma grande descontinuidade litosférica que define 0 limite de diferentes domínios crustais (CORDANI e SATO, 1999), onde a noroeste está o Cráton Amazônico, e a sudeste o Cráton do São Francisco.

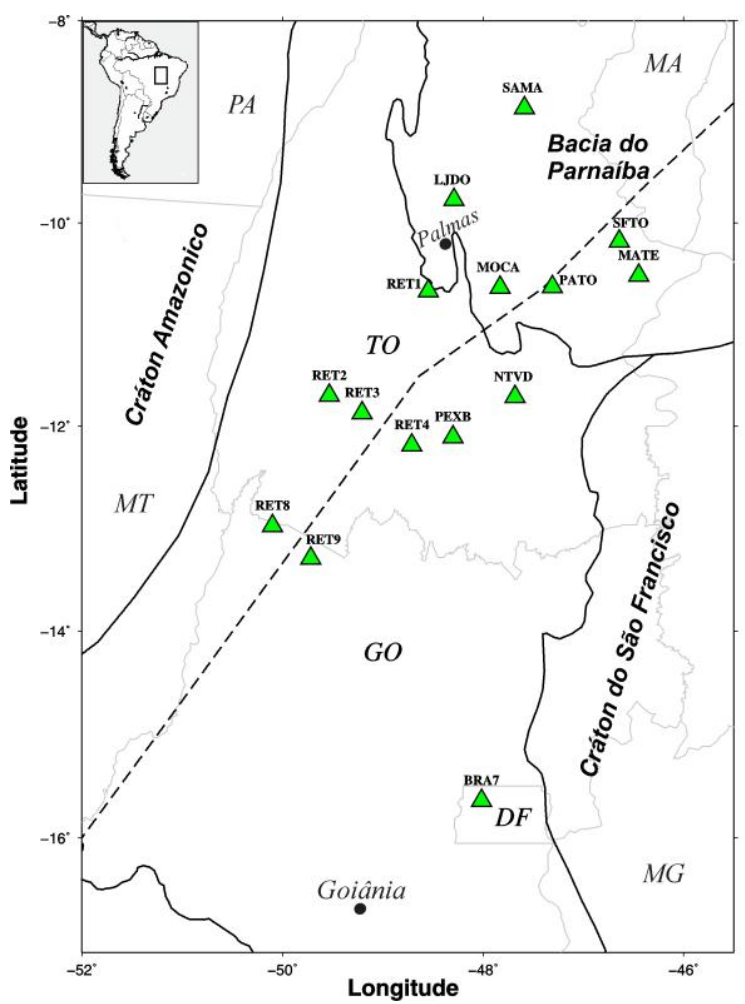

Figura 1: Área de estudo com distribuição das estações, representadas pelos triângulos verdes. A linha tracejada representa 0 Lineamento Transbrasiliano. As linhas sólidas em cinza e em preto são os limites dos estados e das províncias geológicas, respectivamente.

\section{Contexto Geológico}

O Brasil Central é uma das regiões de maior complexidade tectônica da América do Sul. Basicamente, esta área inclui a Província Tocantins, que é limitada a noroeste pelo Cráton Amazônico, a leste pelo Cráton do São Francisco, e pelas bacias do Paraná a sul e do Parnaíba a norte (Figura 1). O mais importante evento relacionado à formação da Província Tocantins é a colisão entre os crátons Amazônico e do São Francisco e uma terceira área estável, o bloco de Paranapanema, localizado sob a Bacia do Paraná (PIMENTEL et al., $2000,2004)$. Este evento deu origem também às faixas de dobramento Araguaia e Paraguai. Ao norte da Província Tocantins encontra-se a Bacia do Parnaíba, que é uma das maiores bacias cratônicas da América do 
Sul. A bacia ocupa uma área de mais de $660.000 \mathrm{~km}^{2}$, ocupando quase metade da província Parnaíba na sua parte centro-sul (BRITO NEVES, 1998) e abrange um bloco de litosfera rígida em seu embasamento, provavelmente representando um núcleo cratônico. Segundo Santos et al. (2011), a hipótese mais aceita para sua origem é a de uma contração térmica e adensamento litosférico ocorrido no final da Orogenia Brasiliana, provocando fragmentação de um supercontinente no Neoproterozóico, conforme proposto por Góes et al. (1993).

\section{Metodologia}

O método utilizado neste trabalho se baseia na inversão de resíduos relativos de tempo de percurso de ondas telessísmicas (VAN DECAR et al., 1995). Os resíduos relativos podem ser obtidos a partir dos resíduos absolutos, que são a diferença entre o tempo de percurso observado, obtido pela marcação visual das fases, e o tempo teórico (calculado) relacionado a um modelo médio da Terra (neste trabalho utilizamos o modelo IASP91 - KENNETH e ENGDAHL, 1991). Com o objetivo de refinar a marcação das primeiras chegadas, utilizamos o método de correlação cruzada MCPCC (Multi-Channel Phase Cross Correlation) desenvolvido por Schimmel et al. (2003). A formulação utilizada neste trabalho segue o método ACH (EVANS e ACHAUER, 1993), no qual resíduos relativos de tempo de percurso são invertidos para restringir as anomalias de velocidade ao segmento final dos raios sísmicos, eliminando influências de estruturas fora do volume estudado. Este método é também conhecido como "Inversão por Mínimos Quadrados para Arranjo Restrito", devido ao fato de que o arranjo de receptores não se estende sobre as fontes sísmicas.

Os dados deste trabalho são provenientes de uma rede de estações temporárias, instaladas no Brasil Central, adquiridos durante aproximadamente 4 anos. Utilizamos os registros de fases $P$ e PKIKP de eventos com magnitude mínima de 4.6 e $5.4(\mathrm{mb})$, respectivamente. Foram escolhidos eventos no intervalo de distância angular de $30^{\circ}$ a $95^{\circ}$ para as ondas $\mathrm{P}$ e de $150^{\circ}$ a $180^{\circ}$ para ondas PKIKP, com o objetivo de evitar efeitos de triplicação e sobreposição de fases, causadas por zonas de transição do manto, onde há um aumento significativo das velocidades das ondas sísmicas.

\section{Resultados}

Em nossos resultados, perturbações de velocidade relativa ao modelo de referência IASP91 (KENNETH e ENGDAHL, 1991), são apresentadas em mapas horizontais. As anomalias observadas representam heterogeneidades laterais do modelo, no qual cores frias representam altas velocidades e cores quentes representam baixas velocidades, que aqui são interpretadas como regiões de baixa e alta temperatura, respectivamente. Nas figuras, regiões com baixa densidade de raios (menos de 20 raios $/ 100 \mathrm{~km}^{3}$ ) são representadas em preto.
Observamos na Província Tocantins e sob a parte sul da Bacia do Parnaíba uma anomalia de baixa velocidade alongada na direção nordeste-sudoeste, que coincide com o trend principal do Lineamento Transbrasiliano (Figura 2). Na porção mais ao norte, já na Bacia do Parnaíba, a anomalia parece dividir-se, com um ramo de direção norte-sul e outro aproximadamente leste-oeste. Os crátons Amazônico e do São Francisco são caracterizados por anomalias de alta velocidade, que são características de regiões mais estáveis (antigas). Estas anomalias aparecem bem delimitadas sob o Cráton Amazônico. Em ambos os crátons, estas anomalias estendem-se para além de seus limites geológicos de superfície. Uma tendência de alta velocidade é observada também entre os ramos de baixa velocidade sob a Bacia do Parnaíba.

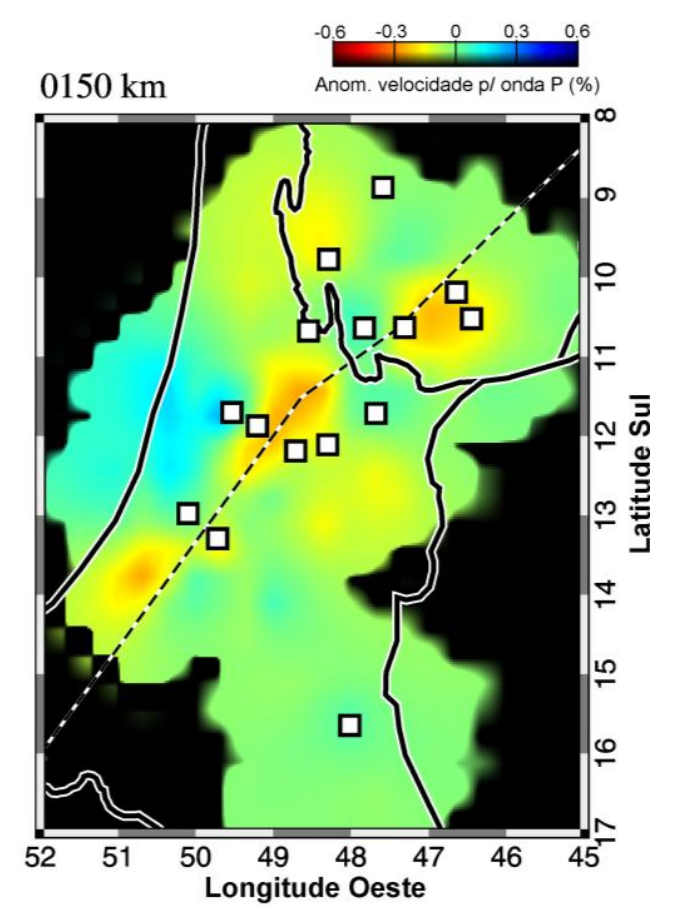

Figura 2: Imagem tomográfica horizontal para a profundidade de $150 \mathrm{~km}$. As linhas grossas indicam os limites das estruturas geológicas e os quadrados brancos representam as estações. A linha tracejada representa o Lineamento Transbrasiliano.

Nossos dados foram incluídos na base de dados utilizada por Rocha et al. (2011). Após esta inclusão (Figura 3), verificamos a presença de uma anomalia de baixa velocidade na parte central da área de estudo, principalmente em Goiás, a qual possuía baixa amplitude antes da inclusão, descartando a hipótese de que esta anomalia é um artefato gerado durante a inversão e mostrando que ela é robusta. Com a inclusão dos dados, foi possível aumentar a amplitude da anomalia sob o Cráton do São Francisco, confirmando a predominância de altas velocidades nesta região, as quais se estendem para além de seus limites geológicos de superfície. 


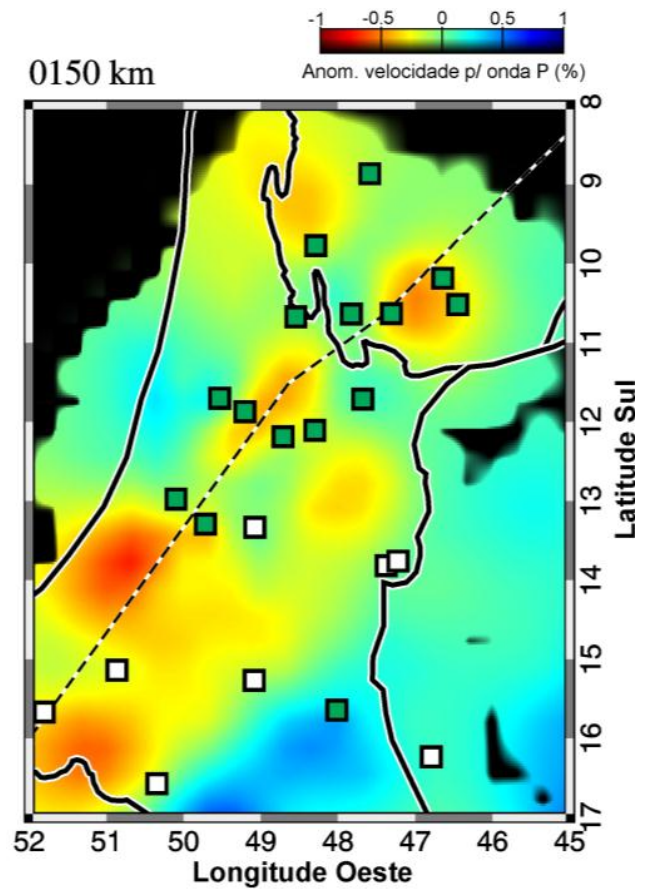

Figura 3: Imagem tomográfica horizontal para a profundidade de $150 \mathrm{~km}$ obtida com a inclusão dos nossos dados na base de Rocha et al. (2011). Os quadrados brancos representam as estações utilizadas neste trabalho e os verdes são estações utilizadas por Rocha et al. (2011).

\section{Discussão e Conclusões}

A anomalia de baixa velocidade com direção nordestesudoeste que foi observada em nossos resultados, coincide com 0 trend principal do Lineamento Transbrasiliano, especialmente no Brasil Central. Entretanto, a anomalia não é contínua ao longo de toda a extensão mapeada do Lineamento Transbrasiliano, sendo que uma tendência de altas velocidades é observada sob a Bacia do Parnaíba, onde o lineamento teria continuidade. Dessa forma, as baixas velocidades observadas podem não estar necessariamente relacionadas ao Lineamento Transbrasiliano. Esta anomalia foi interpretada como o limite entre as paleoplacas Amazônica e Sãofranciscana na porção central do lineamento. A porção norte da anomalia pode estar marcando os limites destas paleoplacas com 0 provável núcleo cratônico que representa o embasamento da Bacia do Parnaíba. Nesta região a anomalia de baixa velocidade possui dois ramos de direção norte-sul e de direção aproximadamente lesteoeste. Entre estes ramos existe uma tendência de altas velocidades, que estaria relacionada ao núcleo cratônico sob a bacia.

As anomalias de baixa velocidade observadas coincidem com altas anomalias gravimétricas interpretadas por Soares et al. (2006a) como resultado do efeito regional do manto Neoproterozóico, além do efeito local causado pela ascensão do manto na região, o que suporta a teoria de afinamento litosférico proposta por Assumpção et al. (2004). Nossos resultados concordam com os de tomografia com ondas de superfície obtidos por Feng et al. (2007), no qual anomalias de baixa velocidade observadas no Brasil Central também acompanham a direção do Lineamento Transbrasiliano.

Após a inclusão dos nossos dados na base de dados de Rocha et al. (2011), a parte leste da anomalia de baixa velocidade, principalmente em Goiás, teve sua amplitude aumentada, permitindo discutir a compartimentação desta anomalia em duas estruturas distintas, sendo uma representada pela base do Arco Magmático de Goiás e a outra podendo estar relacionada com a base do Maciço de Goiás, concordando com o modelo de evolução da Província Tocantins proposto por Soares et al. (2006b).

As anomalias de alta velocidade observadas para além dos limites geológicos de superfície sob o Cráton do São Francisco reforçam a hipótese de que este cráton faz parte de um bloco maior em subsuperfície (Placa Sãofranciscana - ALKMIM et al., 1993), sugerido também em outros trabalhos (e.g. USSAMI, 1993; ROCHA, et al., 2011). A anomalia de alta velocidade observada na parte oeste da área de estudo foi interpretada como sendo parte do Cráton Amazônico. Esta anomalia também ultrapassa os limites geológicos de superfície deste cráton para leste, porém não tão além quanto sob o Cráton do São Francisco. Na Figura 4 está proposto um modelo, com base em nossos resultados, para os limites em subsuperfície das placas Amazônica e Sãofranciscana dentro da área de estudo, bem como o possível limite destas paleoplacas com o núcleo cratônico da Bacia do Parnaíba.

\section{Agradecimentos}

Agradecemos a Coordenação de Aperfeiçoamento de Pessoal de Nível Superior (CAPES) e ao projeto Instituto Nacional de Ciência e Tecnologia em Estudos Geotectônicos (INCT-ET) pela bolsa de mestrado concedida ao autor P. A. Azevedo. Ao CNPq pela Bolsa de Produtividade em Pesquisa concedida ao autor R. Fuck. A Petrobrás, por fornecer os recursos para o desenvolvimento deste trabalho e ao técnico Robson Reis pelo auxílio nos trabalhos de campo.

\section{Referências}

Alkmim, F. F.; Brito Neves, B. B. e Barbosa, J. S. F. (1993). Arcabouço tectônico do Cráton do São Francisco - uma revisão, in: O Cráton do São Francisco, pp. 45-62, eds Dominguez, J. M. L. e Misi, A., SBG Núcleo Bahia/Sergipe, Salvador.

Assumpção, M.; Schimmel, M.; Escalante, C.; Rocha, M.; Barbosa, J. R. e Barros, L. V. (2004). Intraplate seismicity in SE Brazil: stress concentration in lithospheric thin spots, Geophysical Journal International, 159:390-399, doi:10.1111/j.1365-246X.2004.02357.x.

Brito Neves, B.B. (1998). The Cambro-Ordovician of the Borborema Province. São Paulo, USP, Boletim IG, Série Científica-29:175-193. 
Cordani, U. G. e Sato, K. (1999). Crustal evolution of the South American Platform, based on $\mathrm{Nd}$ isotopic systematics on granitoids rocks. Episodes, 22(3):167-173.

Evans, J. R. e Achauer, U. (1993). Teleseismic velocity tomography using the $\mathrm{ACH}$ method: theory and application to continental-scale studies, In: H. M. lyer e K. Hirahara eds. Seismic Tomography: Theory and Practice: Chapman and Hall, London, pp. 319-360.

Feng, M.; Van der Lee, S. e Assumpção, M. (2007). Upper mantle structure of South America from joint inversion of waveforms and fundamental mode group velocities of Rayleigh waves. Journal of geophysical Research, 112(B04312), doi:10.1029/2006JB004449.

Góes, A. M. O.; Travassos, W. A. S. e Nunes, K. C. (1993). Projeto Parnaíba: Reavaliação da bacia e perspectivas exploratórias. Unpubl. Technical Report PETROBRÁS.

Kenneth, B. L. N. e Engdahl, E. R. (1991). Travel times for global earthquakes location and phase identification. Geophysical Journal International, 105:429-465.

Pimentel, M. M.; Fuck, R. A.; Jost, H.; Ferreira Filho, C. F. e Araújo, S. M. (2000). The basement of the Brasília Fold Belt and the Goiás Magmatic Arc. in: Tectonic Evolution of South America, 195-229, 31st International Geological Congress, Rio de Janeiro, Brazil.

Pimentel M. M.; Jost H. e Fuck R. A. (2004). O embasamento da Faixa Brasília e o Arco Magmático de Goiás, In: V. Mantesso Neto, A. Bartorelli, C. D. R., Carneiro, B. B. de Brito Neves (Organizadores) Geologia do Continente Sul-Americano: evolução da obra de Fernando Flávio Marques de Almeida. Editora Beca, São Paulo-673pp.

Rocha, M. P.; Schimmel, M. e Assumpção, M. (2011). Upper-mantle seismic structure beneath SE and Central Brazil from $\mathrm{P}$ - and S-wave regional traveltime tomography. Geophysical Journal International, 184:268286, doi: 10.1111/j.1365-246X.2010.04831.x.

Santos, R. D.; Castro, D. L.; Bezerra, F. H. R.; Vidotti, R. M. e Fuck, R. A. (2011). Expressão geofísica do Lineamento Transbrasiliano na porção sul da Bacia Parnaíba, in: SBGf, 12th International Congress of the Brazilian Geophysical Society, Rio de Janeiro, Brazil.

Schimmel, M.; Assumpção, M. e VanDecar, J. C. (2003). Seismic velocity anomalies beneath SE Brazil from $P$ and $S$ wave travel time inversions. Journal of geophysical Research, 108(B4):1-13, doi:10.1029/2001JB000187.

Soares, J. E., Berrocal, J., Fuck, R. A., Mooney, W. D., \& Ventura, D. B. R. (2006a). Seismic characteristics of central brazil crust and upper mantle: A deep seismic refraction study. Journal of Geophysical Research B: Solid Earth, 111(12).
Soares, J. et al., 2006b. Geophysical evidence of amazon subduction in central brazil: a new insight into tocantins province evolution. Tectonophysics (in press).

Ussami, N. (1993). Estudos Geofísicos no Cráton do São Francisco: Estágio Atual e Perspectivas, in O Cráton do São Francisco, pp. 35-43, eds Domingues, J. e Misi, A., Sociedade Brasileira de Geologia, Brazil.

VanDecar, J. C.; James, D. E. e Assumpção, M. (1995). Seismic evidence for a fossil mantle plume beneath South America and implications for plate driving forces. Nature, 378:25-31-doi:10.1038/378025a0. 
- Lineamento Transbrasiliano

Limites dos Blocos Cratônicos

曰Limites Geológicos dos Crátons
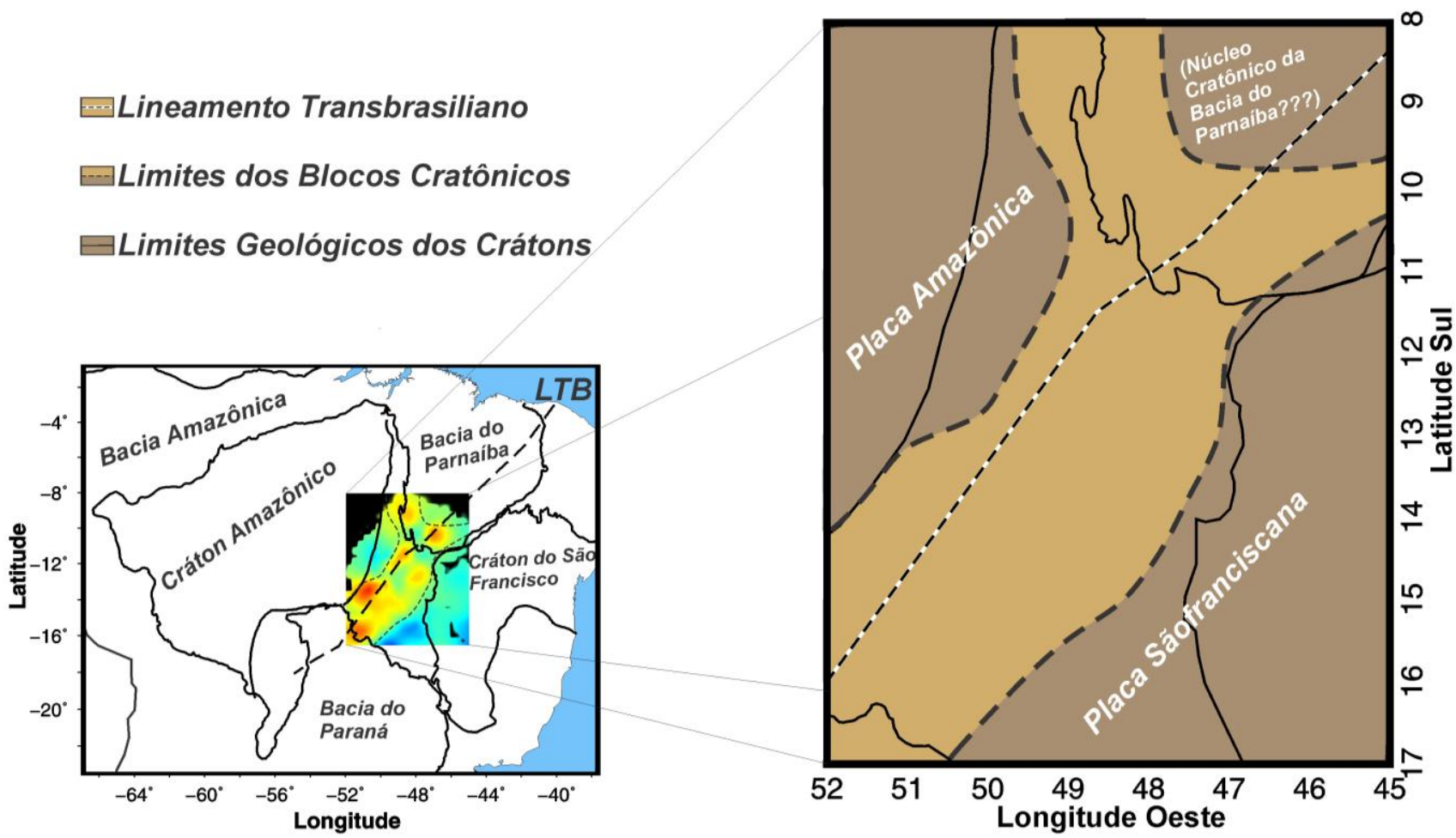

Figura 4: Modelo proposto para os limites em subsuperfície das placas Amazônica e Sãofranciscana na área de estudo, e provável limite do núcleo cratônico da Bacia do Parnaíba. LTB é o Lineamento Transbrasiliano. 